\title{
Assessment of extreme value overestimations with equivalent static wind loads
}

\author{
Nicolas Blaise ${ }^{\mathrm{a}, *}$, Thomas Andrianne ${ }^{\mathrm{b}}$, Vincent Denoël ${ }^{\mathrm{a}}$ \\ ${ }^{\text {a }}$ Structural \& Stochastic Dynamics, University of Liège, Liège, Belgium \\ ${ }^{\mathrm{b}}$ Wind Tunnel Lab, University of Liège, Liège, Belgium
}

\section{A R T I C L E I N F O}

\section{Keywords:}

Non-Gaussian buffeting analysis

Extreme value

Equivalent static wind loads

Conditional expected static wind loads

Bicubic model

\begin{abstract}
A B S T R A C T
The wind-resistant design using equivalent static wind loads is convenient for structural engineers. This paper studies the reliability of such an approach in the case of non-Gaussianities in both aerodynamic pressures and responses. These non-Gaussianities are responsible for overestimations of envelope values and may result in uneconomical designs, if not appropriately understood, assessed and addressed. In this study, it is shown that the equivalent static wind loads defined with the Conditional Expected Load method, which extends the physical meaning of the Load-Response Correlation approach in a non-Gaussian framework, improves the issue of overestimations of envelope values. Several envelopes of structural responses are considered: the mean of extremes and the $86 \%$ quantiles of extremes, together with two reference periods ( $10 \mathrm{~min}$ and $1 \mathrm{~h}$ ). Extensive wind tunnel measurements have been collected, which correspond to $371 \mathrm{~h}$ full scale. This study is undertaken for quasi-static analysis of structures and is illustrated with a low-rise building.
\end{abstract}

\section{Introduction}

The aerodynamics of unusual structures built in the atmospheric boundary layer is so complex that a case-by-case study needs to be specifically developed for every new project. Although standards and codification processes properly describe the main features of the atmospheric wind flows, as well as their statistical distributions, the determination of actions on buildings and other civil engineering structures is practically obtained by means of wind-tunnel experiments or computational fluid dynamics simulations. Whatever method is chosen, this huge quantity of information is usually too heavy and too detailed for the structural engineer who designs the bearing system of the building, or even for the façade engineer who designs the envelope. Some 50 years after the gust loading factor has been suggested by Davenport (1967), it is still very common to proceed with the structural design on the basis of equivalent static wind loads (ESWLs) rather than the time-dependent wind loads.

Although these detailed time series are too heavy for the design, especially for the combination of wind loads with other load cases, it is possible to determine structural displacement and internal forces at different places of the structure. The statistical treatment of the time series associated with these structural responses (e.g. a bending moment in a decisive element of the structure), also sometimes referred to as effect, provides design values that should be used for the final structural design.
The set of design values associated with all structural responses defines the envelope of structural responses. In this paper - and in most works related to this subject-, it is assumed that this envelope is known and sufficiently accurate to serve as a reference.

Equivalent static wind loads are usually defined with respect to a single structural response. The equivalence is defined in such a way that the structural analysis under an equivalent static load provides the same structural response as the design response that would be obtained by extreme value analysis considering the time-dependent response. The determination of an equivalent static wind load is far from trivial because it should include not only the variability in time and space of the loading but also the possible dynamics of the structure, the possibly non-Gaussian nature of the loads, the possible nonlinear structural behavior, etc. Several methods are therefore available to define an equivalent static load. Among others, three families being respectively the Gust Loading Factor (GLF), the Conditional Sampling Technique (CST) and the LoadResponse-Correlation (LRC) are well-documented. The GLF methods and the likes (Davenport, 1967; Vickery, 1970; Simiu, 1973; Solari, 1993a, b; Holmes, 1994; Simiu and Scanlan, 1996) consist in amplifying a profile of structural responses, e.g., the structural response under the average wind loads, by a scalar in order to estimate the envelope. Although this is not the original spirit of the method, this scalar might be adjusted, if required, from one structural response to another (Tamura

\footnotetext{
* Corresponding author.

E-mail addresses: n.blaise0@gmail.com (N. Blaise), t.andrianne@ulg.ac.be (T. Andrianne), v.denoel@ulg.ac.be (V. Denoël).
} 
et al., 1992; Huang and Chen, 2007). The CST (Holmes and Best, 1981; Stathopoulos, 1984; Holmes, 1988) suggests to process the long timedependent series by retaining the patterns of pressure distributions that corresponds to the maximum (or design) value of the considered structural response. In case several occurrences are detected, averaging is conducted. There are as many CST-based equivalent static wind loads as the considered number of structural responses. In the LRC method (Kasperski and Niemann, 1992), the equivalent static wind load is defined as a function of the correlation coefficient between the considered structural response and the aerodynamic pressure field. The concept has been also extended to the resonant component of the response (Chen and Kareem, 2001), in which case the displacement field is the total, background plus resonant, displacement field of the structure under the buffeting wind load. In a Gaussian framework only, the LRC equivalent static wind load has the virtue to be interpreted as the most probable wind load pattern associated with the design structural response. In a non-Gaussian analysis, the LRC ESWL loses its probabilistic sense.

The Conditional Expected Static Wind Load (CESWL), defined as the average of the wind load patterns given the occurrence of the design value, generalizes this features of the LRC method to non-Gaussian pressures and responses fields (Blaise et al., 2016).

When a large number of responses are of interest, the envelope reconstruction problem arises (Blaise et al., 2016), which consists in finding a set of static loadings (minimum in number and satisfying some accuracy criteria) whose own envelope somehow covers the actual envelope of structural responses. Several advanced techniques (Repetto and Solari, 2004; Katsumura et al., 2007; Chen and Zhou, 2007; Li et al., 2009; Zhou et al., 2011; Blaise and Denoël, 2013; Lou et al., 2015; Patruno et al., 2017) are available to solve the envelope reconstruction problem, for instance multi-objective equivalent static wind load that targets the reconstruction of several envelope values at a time. These techniques rely on all sorts of approximations and overestimations of some envelope responses are unavoidable. Significant overestimations of the reconstructed envelope are typically undesired since they lead to uneconomical designs and one should make sure that the overestimation remains controlled (Blaise et al., 2016).

In some circumstances, the structural engineer may not want to use such advanced techniques because they are heavier and more tricky to exploit. To disentangle himself from the envelope reconstruction problem, the structural engineer can alternatively consider the sequential reconstruction of the envelope using equivalent static wind loads. This approach is viable to some degree, i.e., the number of responses must be manageable, or responses governing the design are easily identified. The sole disadvantage is that, for large structures, the number of load cases is likely to be much larger than with multi-objective techniques. This paper exclusively focuses on using equivalent static wind loads to reconstruct the envelope. In particular, an interesting feature of the LRC method is that it does not provide any overestimation of the envelope and the LRC based reconstructed envelope is, therefore, the actual one as long as a Gaussian context is used (Blaise et al., 2016). The merit and advantage in this approach is that the structural engineer does not have to address overestimations and is ensured to do an economical design. However as soon as a non-Gaussian context is considered, examples show that this non-overestimation property fails. It is no longer possible to ascertain that the envelope of structural responses is not overestimated. This is attributed to the distortion of probability density functions, in the nonGaussian framework. To alleviate this issue, the CESWL was precisely imagined to cope with non-Gaussian loadings or structural responses. It is therefore expected to provide smaller overestimations of the envelope. This statement is studied by means of a large experimental campaign which is reported and summarized in this paper. From a practical standpoint, the implications of the present study might also be considered when developing multi-objective techniques in a nonGaussian context.

Section 2 exposes the establishment of the envelope values of nonGaussian structural responses. Section 3 introduces the conditional expected load method and discusses the bicubic model to estimate conditional expected static wind load. Section 4 illustrates the developments with the non-Gaussian quasi-static analysis of a low-rise gableroof building.

\section{Extreme values of non-Gaussian structural responses}

Structures with linear quasi-static behavior under a stationary nonGaussian aerodynamic pressure field are considered. Decisive structural responses, such as internal forces or stresses are studied. The mean $\mu_{\mathrm{r}}$ and fluctuating parts $\mathbf{r}(t)$ of the structural responses (wind effects) are obtained by linear combinations of the aerodynamic pressures as

$\mu_{\mathbf{r}}=\mathbf{B} \mu_{\mathrm{p}}, \quad \mathbf{r}=\mathbf{B} \mathbf{p}$,

where $\mathbf{B}$ is an $n_{r} \times n_{l}$ matrix of influence coefficients and $\mu_{\mathbf{p}}, \mathbf{p}(t)$ are $n_{l} \times$ 1 vectors gathering the mean and fluctuating part of the aerodynamic pressures measured at $n_{l}$ pressure taps, respectively. For the purpose of design, statistics of extreme values of $\mathrm{r}_{i}(t) \forall i \in\left[1, n_{r}\right]$, are defined for the negative extreme $\check{\mathrm{r}}_{i}=\min \left\{\mathrm{r}_{i}(t), 0<t<T\right\}$ and the positive extreme $\hat{\mathrm{r}}_{i}=$ $\max \left\{\mathrm{r}_{i}(t), 0<t<T\right\}$ for a reference period $T$, typically $10 \min$ or $1 \mathrm{~h}$. The mean of the extremes is usually considered for design when structural responses are Gaussian

$\mathbf{r}^{(\min )}=\mathbb{E}[\check{\mathbf{r}}] ; \mathbf{r}^{(\max )}=\mathbb{E}[\hat{\mathbf{r}}]$.

For non-Gaussian wind effects, $p$-quantiles are used such that

$\bar{F}_{\check{\mathbf{r}}}\left(\mathbf{r}^{(\min )}\right)=p ; F_{\hat{\mathbf{r}}}\left(\mathbf{r}^{(\max )}\right)=p$,

where $\bar{F}_{\breve{\mathbf{r}}}(\mathbf{r})=\operatorname{Prob}(\check{\mathbf{r}} \geqslant \mathbf{r})$ is the complementary distribution of the negative extremes and $F_{\hat{\mathbf{r}}}(\mathbf{r})=\operatorname{Prob}(\hat{\mathbf{r}} \leqslant \mathbf{r})$ is the distribution of the positive extremes. Assuming Gumbel distributions for the extreme values, the mean and mean plus standard deviation of the extremes are associated with the $57 \%$ and $86 \%$-quantiles. For non-Gaussian responses, $78 \%$ or 86\%-quantiles are usually considered (Ding and Chen, 2014).

The couple $\left(\mathbf{r}^{(\min )}, \mathbf{r}^{(\max )}\right)$ defines the envelope which is considered in this work. Notice that the total envelope $\left(\mathbf{r}^{\prime(\min )}, \mathbf{r}^{\prime(\max )}\right)$ is then obtained by adding the mean component $\boldsymbol{\mu}_{\mathrm{r}}$. This is not further discussed since the average wind load is typically accurately measured and well understood.

\section{Structural responses under conditional expected static wind loads}

An equivalent static wind load is a loading such that its application provides the same structural response as that resulting from the extreme value buffeting analysis. As introduced before, several techniques exist to compute an equivalent static wind load. Chen and Zhou (2007) stressed that "The load distribution for a given peak response is not necessarily unique simply because multiple load distributions can result in an identical response.".

Among others, the conditional expected static wind load (CESWL) is a new kind of equivalent static wind load that was specifically designed for non-Gaussian wind pressures and responses (Blaise et al., 2016). This static wind load corresponds to the LRC method in a Gaussian framework. For each wind effect, the CESWL is unique and manifests two important properties.

The conditional expected static wind load $\mathbf{p}^{(\mathscr{E}, \max )}$ (resp. $\mathbf{p}^{(\mathscr{E}, \text { min) }}$ ) is defined as the average of the wind loads conditioned upon recovery of the envelope value $\mathrm{r}_{i}^{(\max )}$ (resp. $\mathrm{r}_{i}^{(\min )}$ )

$\mathbf{p}^{(\mathscr{E}, \max )}=\mathbb{E}\left[\mathbf{p}(t) \mid \mathbf{r}_{i}=\mathbf{r}_{i}^{(\max )}\right]$.

The $k$-th component of the CESWL (4) associated with the envelope value $r_{i}^{(\max )}$ is therefore expressed as the first moment of the conditional distribution, as 
$\mathrm{p}_{k}^{(\mathscr{E}, \max )}=\int_{\mathbb{R}} \mathrm{p}_{k} \psi_{\mathrm{p}_{k} \mid \mathrm{r}_{i}}\left(\mathrm{p}_{k}, \mathrm{r}_{i}^{(\max )}\right) \mathrm{dp}_{k}$

where $\psi_{\mathrm{p}_{k} \mid \mathrm{r}_{i}}\left(\mathrm{p}_{k}, \mathrm{r}_{i}^{(\max )}\right)$ is the conditional probability density function of the $k$-th aerodynamic pressure given the envelope value $\mathrm{r}_{i}=\mathrm{r}_{i}^{(\max )}$. The static structural analysis under a CESWL provides the conditional expected responses in the structure

$\mathbf{r}^{(\mathscr{E}, \max )}=\mathbf{B} \mathbf{p}^{(\mathscr{E}, \max )}=\mathbb{E}\left[\mathbf{r} \mid \mathbf{r}_{i}=\mathbf{r}_{i}^{(\max )}\right]$

where $\mathbb{E}\left[\mathrm{r}_{j} \mid \mathrm{r}_{i}=\mathrm{r}_{i}^{(\max )}\right]$ is the average of the $j$-th response conditioned on $\mathrm{r}_{i}=\mathrm{r}_{i}^{(\max )}$. The static response under the conditional expected static wind $\operatorname{load} \mathbf{p}^{(\mathscr{E}, \max )}$ is therefore such that

$\mathrm{r}_{i}^{(\mathscr{E}, \max )}=\mathrm{r}_{i}^{(\max )}$

i.e., the static response corresponds to the envelope to reconstruct. This defines the envelope value condition (Blaise et al., 2016).

Furthermore, the application of the CESWL $\mathbf{p}^{(\mathscr{E}, \text { max })}$ does not produce responses $\mathrm{r}_{j}^{(\mathscr{E}, \max )}$ in other locations larger than their envelope values, i.e.,

$\mathrm{r}_{j}^{(\min )} \leqslant \mathrm{r}_{j}^{(\mathscr{E}, \max )} \leqslant \mathrm{r}_{j}^{(\max )} \quad \forall j \in\left[1, n_{r}\right]$,

$\mathrm{r}_{j}^{(\min )} \leqslant \mathbb{E}\left[\mathrm{r}_{j} \mid \mathrm{r}_{i}=\mathrm{r}_{i}^{(\max )}\right] \leqslant \mathrm{r}_{j}^{(\max )} \quad \forall j \in\left[1, n_{r}\right]$

which defines the non-overestimation condition (of the envelope). In conclusion, the envelope should not be overestimated since the two conditions (7) and (8) are met for each CESWL. These two properties are enjoyed by the LRC method in a Gaussian context, which is one reason why it gained so much interest.

\subsection{Estimation of the conditional expected static wind loads}

The conditional sampling method can be seen as a non-parametric estimator of the conditional expected static wind load defined in (5). This method requires realizations of the load and response processes and, because of the limited number of available data, the two important properties mentioned above are not formally met. In the family of parametric models, the LRC approach actually implements the conditional expected static wind load defined in (5), by adopting a Gaussian conditional probability density function $\psi_{\mathrm{p}_{k} \mid \mathrm{r}_{i}}\left(\mathrm{p}_{k}, \mathrm{r}_{i}\right)$. Notice however that the LRC method first defines an equivalent static wind load and, second, it happens that it is such that, in a Gaussian context, it indeed corresponds to the most probable wind load. In case of non-Gaussian loads and responses, the Gaussian conditional distribution is only an approximation of the real distribution $\psi_{\mathrm{p}_{k} \mid \mathrm{r}_{i}}\left(\mathrm{p}_{k}, \mathrm{r}_{i}^{(\max )}\right)$ and the two important properties mentioned above are not formally met either. Another parametric model, based on a bicubic transformation, was proposed in (Blaise et al., 2016) in order to provide a closer approximation of the actual conditional loadresponse density function for $\psi_{\mathrm{p}_{k} \mid \mathrm{r}_{i}}\left(\mathrm{p}_{k}, \mathrm{r}_{i}\right)$. Being another approximation, the two important properties mentioned above are still not formally met but, since this 7-parameter model is more flexible than the LRC method, it is hypothesized that it results in smaller overestimation of the envelope in case of non-Gaussianities. This statement is studied in this paper.

\subsubsection{Bicubic model}

The bicubic model is based on the Hermite moment model introduced by Winterstein (1988) for non-Gaussian processes. The aerodynamic pressure $\mathrm{p}_{k}$ and the considered structural response $\mathrm{r}_{i}$ are modeled as two cubic monotonic transformations $g(\cdot)$ and $h(\cdot)$ of two correlated standard Gaussian variables $u$ and $v$ such that $\mathrm{p}_{k}=g(u)=\frac{\alpha_{u}}{b_{u}}\left(\frac{u^{3}}{3}+a_{u} u^{2}+\left(b_{u}-1\right) u-a_{u}\right)$

$\mathrm{r}_{i}=h(v)=\frac{\alpha_{v}}{b_{v}}\left(\frac{v^{3}}{3}+a_{v} v^{2}+\left(b_{v}-1\right) v-a_{v}\right)$

where the parameters $\alpha_{u}, a_{u}, b_{u}$ are tuned to match the variance $\sigma_{\mathrm{p}}^{2}$, skewness coefficient $\gamma_{3, \mathrm{p}}$ and excess coefficient $\gamma_{e, \mathrm{p}}$ of the zero-mean random variable $\mathrm{p}_{k}$ and the parameters $\alpha_{v}, a_{v}$ and $b_{v}$ are tuned to match the variance $\sigma_{\mathrm{r}}^{2}$, skewness coefficient $\gamma_{3, \mathrm{r}}$ and excess coefficient $\gamma_{e, \mathrm{r}}$ of the zero-mean random variable $r_{i}$. This approach is usually referred as the moment-based Hermite model and the values of these 6 parameters can be established with usual methods of the cubic translation model (Gurley et al., 1997), which are used in this paper. Notice that closed form formulations are also available in the literature (Winterstein and Kashef, 2000; Yang et al., 2013). Furthermore, the limited region of skewness $\gamma_{3}$ and excess $\gamma_{e}$ coefficients for the application of the Hermite moment model is defined by the monotone limitation. In case of slight deviations from the monotone limitation, a vertical mapping could be used (Peng et al., 2014). As a possible alternative, a recent approach consists in curve-fitting the cubic transformations, instead of focusing on the 3rd and 4th moments, while guaranteeing the monotone limitation (Ding and Chen, 2014). This method gives reliable estimation for statistics of extremes of non-Gaussian structural responses (Ding and Chen, 2014). This approach has also been considered in this study and provides results very similar to those obtained with the moment-based approach. They are not presented in the following results.

While the usual moment-based method is used to determine the coefficients $\alpha_{u}, a_{u}, b_{u}$ and $\alpha_{v}, a_{v}$ and $b_{v}$, very specific to the bicubic model is the correlation $\rho_{u v}$ between the two Gaussian variables $u$ and $v$. It is such that the correlation of $\mathrm{p}_{k}$ and $\mathrm{r}_{i}$, defined in (10)-(11) corresponds to their actual correlation coefficient $\rho_{\mathrm{pr}}$. It is expressed as (Blaise et al., 2016)

$\rho_{u v}\left(\rho_{\mathrm{pr}}\right)=\left(d+\sqrt{q+d^{2}}\right)^{1 / 3}+\left(d-\sqrt{q+d^{2}}\right)^{1 / 3}-a_{u} a_{v}$,

where $d=\frac{3}{4} a_{u} a_{v} b_{u} b_{v}-a_{u}^{3} a_{v}^{3}+\frac{3 b_{u} b_{v} \rho_{\mathrm{pr}} \sigma_{\mathrm{p}} \sigma_{\mathrm{r}}}{4 \alpha_{u} \alpha_{v}}$ and $q=\left(\frac{b_{u} b_{v}}{2}-a_{u}^{2} a_{v}^{2}\right)^{3}$ with the condition $\frac{b_{u} b_{v}}{2}-a_{u}^{2} a_{v}^{2} \geqslant 0$. Based on the 7 parameters of this model, the joint distribution $\psi_{\mathrm{p}_{k} \mathrm{r}_{i}}$ of the load and response can be established in closed form, after which the conditional expression $\psi_{\mathrm{p}_{k} \mid \mathrm{r}_{i}}$ follows. Substitution of this expression in (5) finally yields an explicit solution for the bicubic-based CESWL $\mathrm{p}_{k}^{(\mathrm{E}, \max )}$-which is a parametric estimator of $\mathrm{p}_{k}^{(\mathscr{E}, \max )}$ - associated with $\mathrm{r}_{i}^{(\max )}=h\left(v^{(\max )}\right)$

$$
\begin{aligned}
\mathrm{p}_{k}^{(\mathrm{E}, \max )}= & \frac{\alpha_{u}}{3 b_{u}}\left(\left(\left(v^{(\max )}\right)^{3}-3 v^{(\max )}\right) \rho_{u v}^{3}+3 a_{u}\left(\left(v^{(\max )}\right)^{2}-1\right) \rho_{u v}^{2}\right. \\
& \left.+3 b_{u} v^{(\max )} \rho_{u v}\right)
\end{aligned}
$$

see (Blaise et al., 2016) for details, where

$v^{(\max )}=\left[\zeta_{v}+\sqrt{c_{v}+\zeta_{v}^{2}}\right]^{1 / 3}+\left[\zeta_{v}-\sqrt{c_{v}+\zeta_{v}^{2}}\right]^{1 / 3}-a_{v}$,

with $c_{v}=\left(b_{v}-1-a_{v}^{2}\right)^{3}, \zeta_{v}=\frac{3}{2} b_{v}\left(a_{v}+\mathrm{r}_{i}^{(\max )} / \alpha_{v}\right)-a_{v}^{3}$.

The bicubic-based CESWL $\mathbf{p}^{(E, \max )}$ is a parametric estimator of the CESWL $\mathbf{p}^{(\mathscr{E}, \text { max })}$ and therefore the envelope value and non-overestimation conditions may not be fulfilled. The static analysis under the bicubicbased CESWL provides model-based estimation of the conditional expected responses $(6)$ in the structure $\mathbf{r}^{(\mathrm{E}, \max )}=\mathbf{B} \mathbf{p}^{(\mathrm{E}, \max )}$. In order to perfectly recover the considered envelope value $r_{i}^{(\max )}$, a scaled bicubic- 

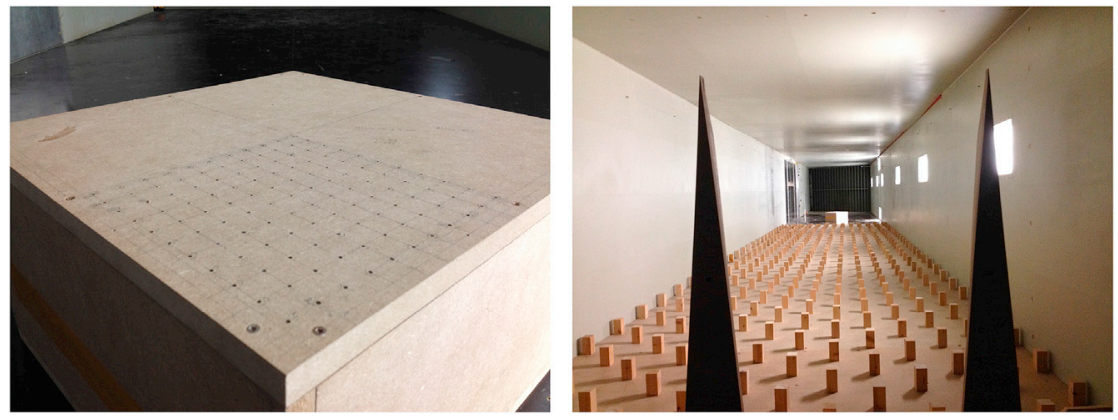

Fig. 1. View of the model and its installation in the atmospheric boundary layer test section of the wind tunnel of the University of Liège.

based CESWL $\tilde{\mathbf{p}}^{(\mathrm{E}, \max )}$ is defined from the original $\mathbf{p}^{(\mathrm{E}, \max )}$ as

$\tilde{\mathbf{p}}^{(\mathrm{E}, \max )}=\alpha^{(\mathrm{E}, \max )} \mathbf{p}^{(\mathrm{E}, \max )}$,

with the scaling coefficient $\alpha^{(\mathrm{E}, \max )}=\mathrm{r}_{i}^{(\max )} / \mathrm{r}_{i}^{(\mathrm{E}, \max )}$.

\subsubsection{Gaussian context}

In case both variables $\mathrm{p}_{k}$ and $\mathrm{r}_{i}$ are Gaussian random variables, the parameters of the cubic transformations become

$\alpha_{u} \rightarrow \sigma_{\mathrm{p}}, \alpha_{v} \rightarrow \sigma_{\mathrm{r}}, b_{u} \rightarrow \infty, b_{v} \rightarrow \infty, a_{u} \rightarrow 0, a_{v} \rightarrow 0$,

which yields $\rho_{\mathrm{pr}}=\rho_{u v}$ in (12). The conditional mean value of $\mathrm{p}_{k}$ given $\mathrm{r}_{i}=\mathrm{r}_{i}^{(\max )}$ in (13) simply becomes the LRC formulation

$\mathrm{p}_{k}^{(\mathrm{E}, \max )}=\frac{\mathrm{r}_{i}^{(\max )}}{\sigma_{\mathrm{r}}} \rho_{\mathrm{pr}} \sigma_{\mathrm{p}}$.

In a Gaussian context, the LRC ESWL given by (17) is the exact CESWL (5) since the joint and conditional PDFs are Gaussian and no approximation is made. The envelope value (7) and non-overestimation (8) conditions are therefore fulfilled with the LRC ESWLs (or CESWL, since they coincide in a Gaussian context.)

\subsection{Assessment of extreme value overestimations}

In a non-Gaussian context, nothing prevents the use of the same formulation as (17) to determine the equivalent static wind load (Kasperski, 1992). Nothing guarantees, however, any boundedness of the overestimation of the envelope, which might in fact be rather severe (see

a

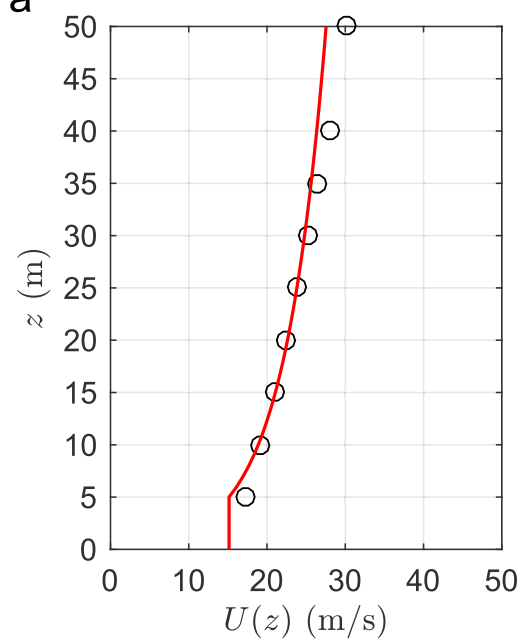

examples). Another option is to use the more general formula (13) but, being another parametric estimator of the conditional joint probability, the boundedness of the overestimation is neither guaranteed. It is just expected to be smaller because the bicubic model possesses 7 degrees-offreedom to better match the non-Gaussian joint distribution of the load and response. The assessment of extreme value overestimations is the main scope of the paper. In the following, we compare the overestimations resulting from the LRC ESWL (used as such even in the nonGaussian framework) and the bicubic-based CESWL. Notice that, in both cases, the envelope value condition is met; see (Kasperski, 1992) for the LRC approach; concerning the bicubic-based CESWL, this issue is solved with the rescaling (15).

The $n_{l} \times n_{r}$ ESWL matrices $\mathbf{P}^{(\mathrm{E}, \mathrm{min})}$ and $\mathbf{P}^{(\mathrm{E}, \mathrm{max})}$ consist of columns collecting either the scaled bicubic-based CESWLs (15) or LRC ESWLs (17), computed for all envelope values, negative and positive extremes, respectively. We define an $n_{l} \times 2 n_{r}$ matrix $\mathbf{P}^{(\mathrm{E})}$ collecting all ESWLs

$\mathbf{P}^{(\mathrm{E})}=\left[\mathbf{P}^{(\mathrm{E}, \min )} \mathbf{P}^{(\mathrm{E}, \max )}\right]$,

The matrix $\mathbf{R}^{(\mathrm{E})}=\mathbf{B P}^{(\mathrm{E})}$ gathers all static structural responses associated with this complete set of equivalent static wind loads. The reconstructed envelope $\left(\tilde{\mathbf{r}}^{(\min )}, \tilde{\mathbf{r}}^{(\max )}\right)$ is expressed as

$\tilde{\mathbf{r}}^{(\max )}=\max _{i}\left(\mathbf{R}_{i}^{(\mathrm{E})}\right), \quad \tilde{\mathbf{r}}^{(\min )}=\min _{i}\left(\mathbf{R}_{i}^{(\mathrm{E})}\right)$.

The assessment of extreme value overestimations is based on a relative difference between the reconstructed and actual envelopes, defined as

b

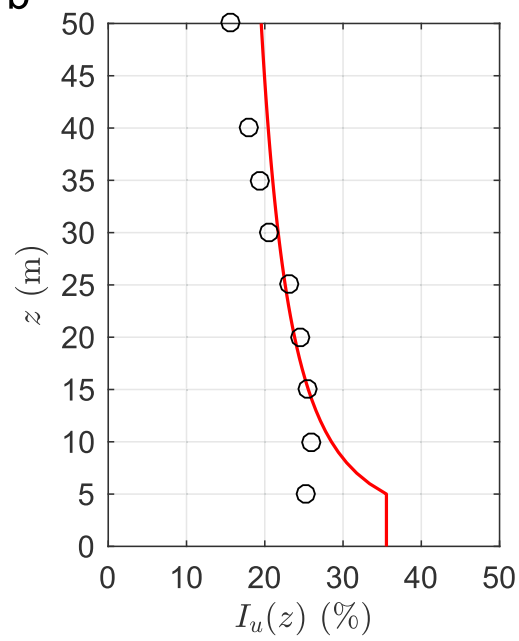

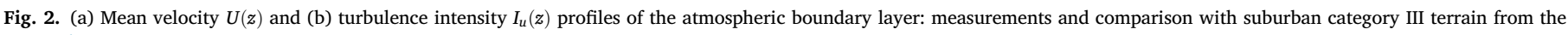
Eurocode (1991). 


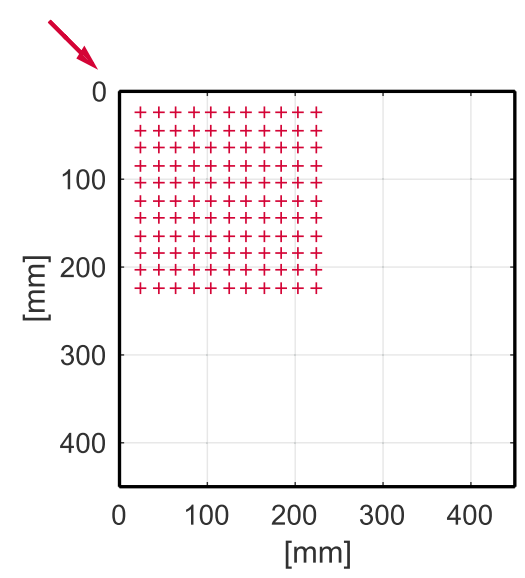

Fig. 3. Location of pressure taps. The wind direction $45^{\circ}$ is studied.

$\boldsymbol{\varepsilon}^{(\max )}=\left(\tilde{\mathbf{r}}^{(\max )}-\mathbf{r}^{(\max )}\right) \div \mathbf{r}^{(\max )} ; \boldsymbol{\varepsilon}^{(\min )}=\left(\tilde{\mathbf{r}}^{(\min )}-\mathbf{r}^{(\min )}\right) \div \mathbf{r}^{(\min )}$

where the symbol $\div$ means the division is performed element by element. For $\varepsilon_{i}^{(\max )}=0 \%$ and $\varepsilon_{i}^{(\max )}>0 \%$, the $i$-th envelope value is perfectly reconstructed or overestimated, respectively.

\section{Illustrations}

A rigid flat-roof low-rise building is analyzed under wind actions. Extensive wind-tunnel tests have been performed to study the

\section{a}
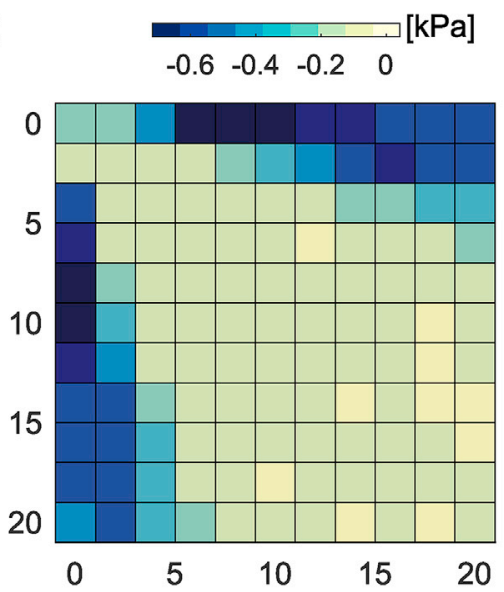

C

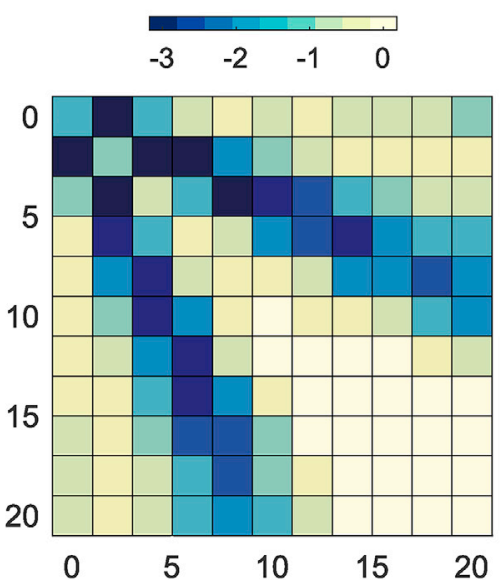

aerodynamic pressure field on this structure. The structure used for illustrations has sharp edges connecting the vertical walls and the roof. Depending on the angle of attack of the wind, the aerodynamic pressure field for this roof configuration is known to exhibit mildly to strongly non-Gaussianities. The roof is supported by a collection of beams.

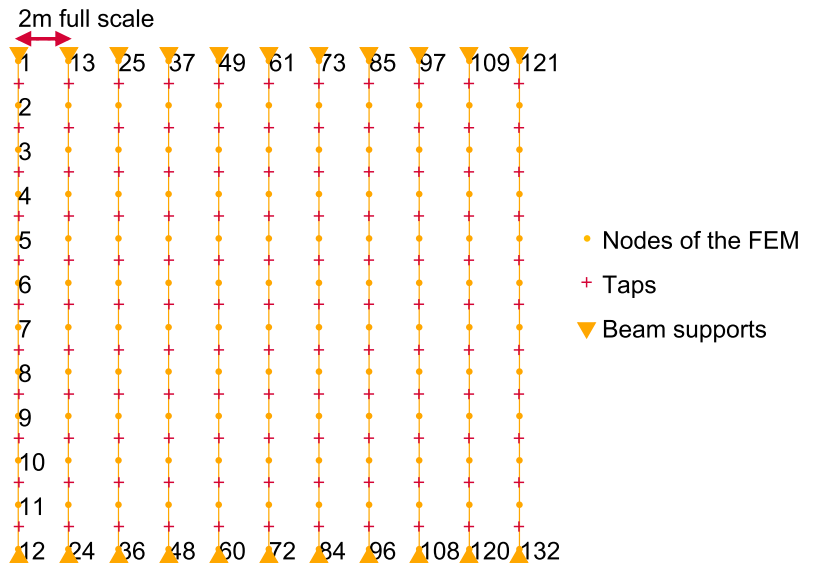

Fig. 5. Plan view of the roof. The orange dots identify the nodes of the finite element model and the numbering of the bending moments is given. The orange triangles depict the supports of each beam and the red crosses represent the taps. (For interpretation of the references to colour in this figure legend, the reader is referred to the web version of this article.)

b
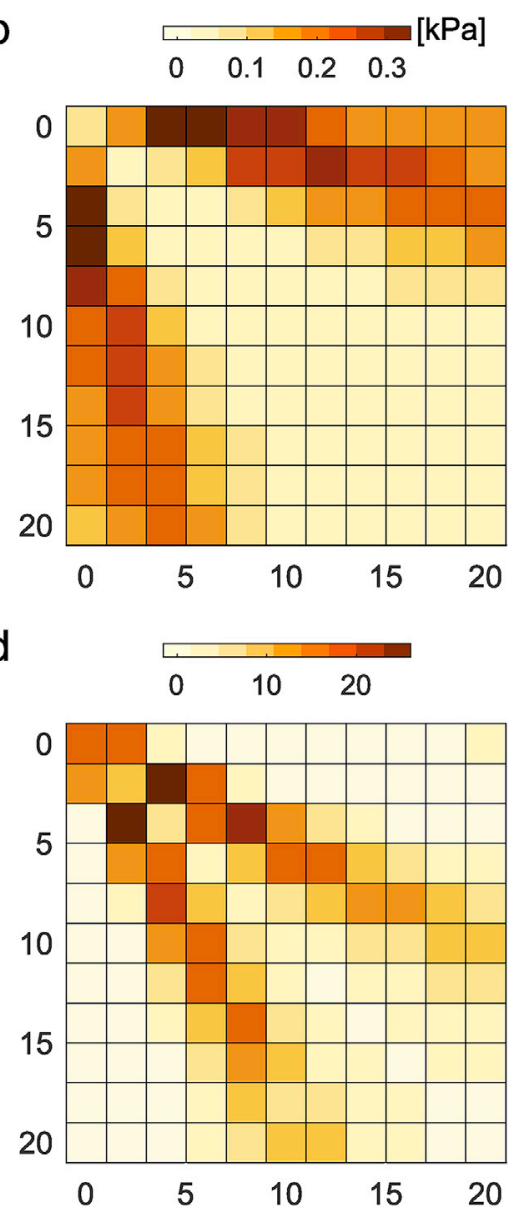

Fig. 4. Maps of (a) mean, (b) standard deviation, (c) skewness $\gamma_{3}$ and (d) excess $\gamma_{e}$ coefficients of the pressure loading on the roof of the building (dimensions in meters). 


\subsection{Wind tunnel tests}

A dedicated test campaign is carried out in the wind tunnel laboratory of the University of Liège. A low-rise building with a square plan-form (sides of $45 \mathrm{~m}$ ) and a height of $25 \mathrm{~m}$ is instrumented by pressure taps in a quarter of its roof (see Fig. 1). The instrumented region of the model is uniformly covered by 121 pressure taps connected to a dynamic pressure scanner measuring at a $500 \mathrm{~Hz}$. The pneumatic connection between the scanner and the pressure taps is made with vinyl tubes with internal diameter of $1.32 \mathrm{~mm}$ and length of $600 \mathrm{~mm}$. The effect of the tube is corrected by the theoretical formulation of Bergh and Tijdemans (1965) to obtain the dynamic response of the tube.
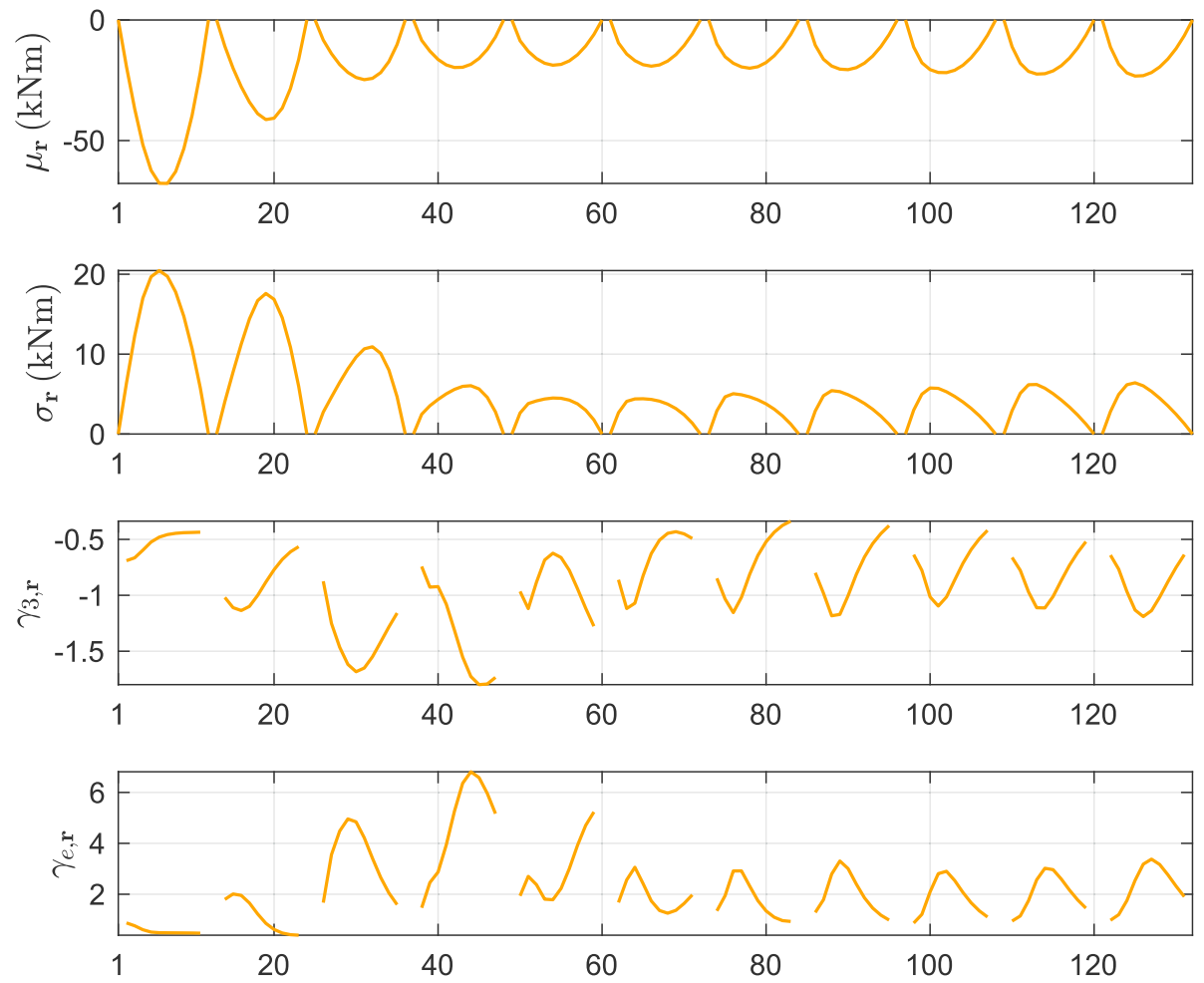

Fig. 6. (a) Mean, (b) standard deviation, (c) skewness coefficient and (d) excess coefficient for the bending moments.

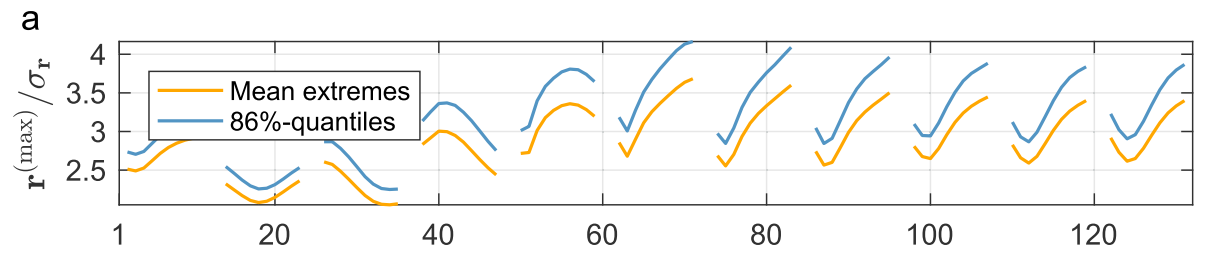

b

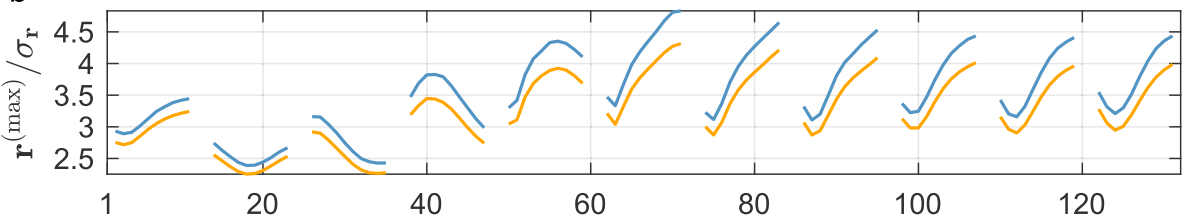

C

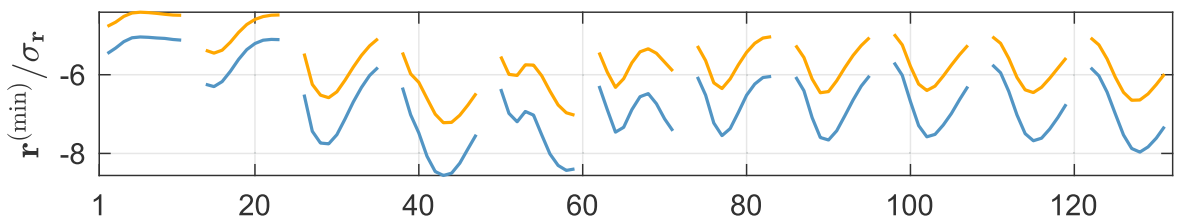

d

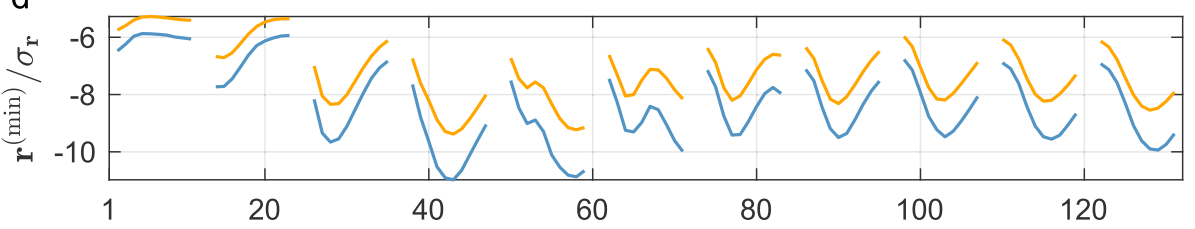

Fig. 7. Statistics of extremes of bending moments: mean extremes and $86 \%$ quantiles for two reference periods: $10 \mathrm{~min}$ (a)-(c) and $1 \mathrm{~h}$ (b)-(d). 
a

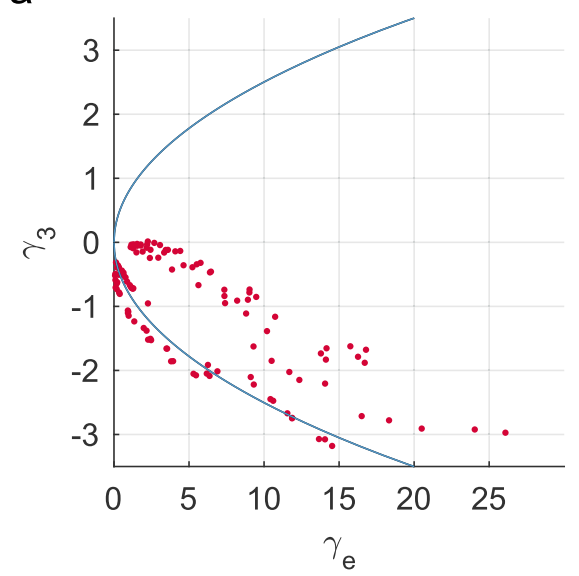

b

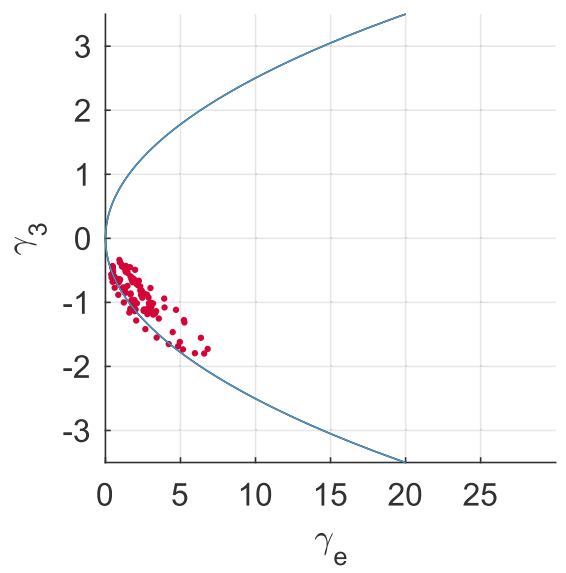

Fig. 8. Skewness $\gamma_{3}$ and excess $\gamma_{e}$ coefficients for the (a) aerodynamic pressures and for the (b) bending moments.

Tests are performed in a turbulent boundary layer generated by blocks, a wall and spires (see Fig. 1). On the basis of the geometric and velocity scales $\left(\lambda_{L}=1 / 100\right.$ and $\lambda_{U}=1 / 3.5$, respectively), the resulting turbulent wind corresponds to a terrain category III according to the Eurocode (1991). The Strouhal relation imposes the time scale through $\lambda_{T}=\lambda_{L} / \lambda_{U}=1 / 28.6$. The mean velocity and longitudinal turbulent intensity profiles are presented in Fig. 2, the matching with the standard prescription is rather good up to twice the height of the building.

At this scale, $21 \mathrm{~s}$ of measurement correspond to a record of $10 \mathrm{~min}$ at full scale. For the purpose of this work a total of more than $13 \mathrm{~h}$ of measurements at the wind tunnel have been collected, which correspond to $371.8 \mathrm{~h}$ full scale. The frequency content of the measured unsteady pressure fields is captured up to $8.7 \mathrm{~Hz}$ full scale, which is largely sufficient to analyse the effect of turbulent wind loadings.

In the scope of this work, the single wind direction of $45^{\circ}$ is retained (see Fig. 3). This choice is justified by the critical pressure loading due to the presence of conical vortices in the vicinity of the edges of the building (Kind, 1986; Kawai and Nishimura, 1996). These powerful unsteady aerodynamic structures appear clearly in Fig. 4. In Fig. 4-(a) and (b), the flow separation region is shown in dark blue and red respectively. This zone is characterized by large negative mean values and an important unsteadiness. On the other hand, the impinging region, where the conical vortices impact the roof, are shown in Fig. 4-(c) and (d). In both plots, two lines separate symmetrically from the diagonal of the square roof. Along theses lines, the skewness and excess coefficients of the measured pressure reach large values: $\gamma_{3}=-3$ and $\gamma_{e}=20$. These statistics highlight the strong non-Gaussianity of pressure loading due to the conical vortices.

\subsection{Description of the structural system and determination of the envelope}

The quarter instrumented roof is supported by 11 simply supported

ESWL - Moment \#20

$$
\begin{aligned}
& \operatorname{LRC}\left(\alpha^{(\mathrm{s}, \min )}=1\right) \\
& \begin{array}{llll}
-1.5 & -1 & -0.5 & 0
\end{array}
\end{aligned}
$$

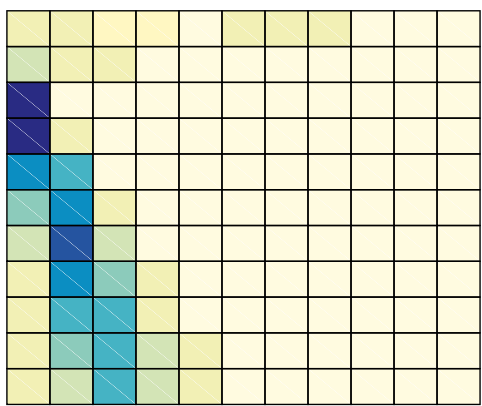

Bicubic-based $\left(\alpha^{(\mathrm{s}, \min )}=1.09\right)$

$[\mathrm{kPa}]$

$$
\begin{array}{llll}
-1.5 & -1 & -0.5 & 0
\end{array}
$$

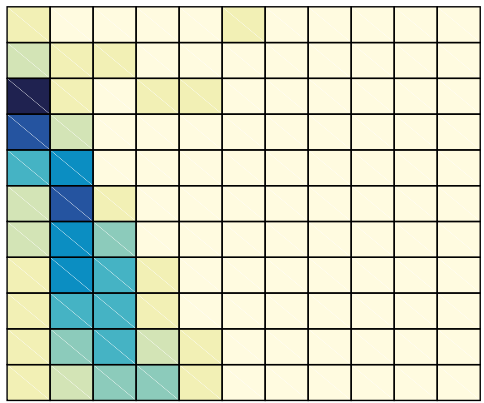

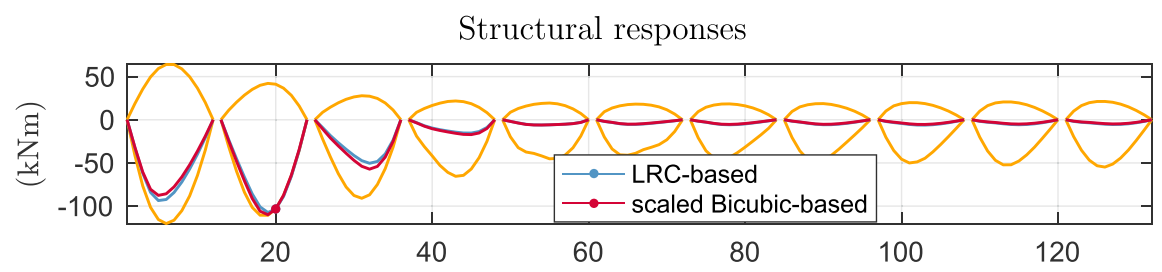

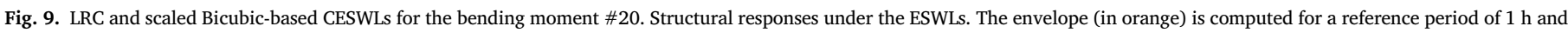
the $86 \%$-quantiles extremes. (For interpretation of the references to colour in this figure legend, the reader is referred to the web version of this article.) 
beams placed every $2 \mathrm{~m}$. Each beam is divided into 11 finite elements. The aerodynamic pressure field acting on the cladding is transferred directly to the beams. The bending moments at the nodes of the finite element model (except those at the supports) are considered for the assessment of extreme value overestimations $\left(n_{r}=110\right)$ with ESWLs.

Using the numbering of cross sections (see Fig. 5), from 1 to 132, Fig. 6 depicts the mean, standard deviation, skewness coefficient and excess coefficient for the bending moments in all beams. The first two beams are the most loaded while bending moments exhibit largest skewness and excess coefficients in the third and fourth beams.

For the reference period of $10 \mathrm{~min}$ (resp. one hour), extremes are picked up from 2319 (resp. 374) windows of $10 \mathrm{~min}$ (resp. one hour). The mean of the extremes and the $86 \%$ quantiles are obtained through the probability density function and the cumulative distribution function, respectively.

Fig. 7 shows the statistics of process extremes normalized by the standard deviations of the process. The large non-Gaussianities of the bending moments produce significant difference in the statistics for the negative and positive extremes as well as an important increase while considering the $86 \%$-quantiles instead of the mean for the extremes. The total envelope results from an element-by-element multiplication of the statistics of process extremes shown in Fig. 7 and the standard deviations and by adding the mean component, which are shown in Fig. 6 .

\section{ESWL - Moment \#15}

\section{LRC}
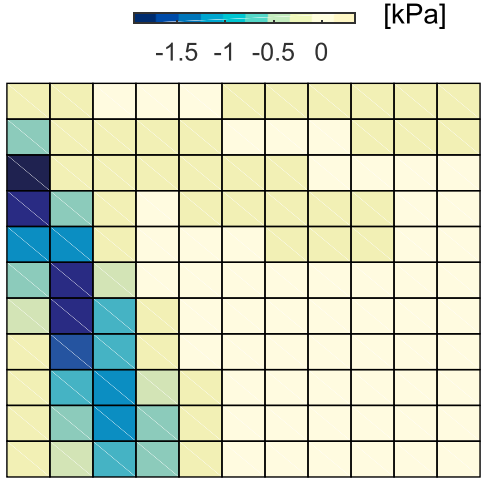

Bicubic-based $\left(\alpha^{(\mathrm{s}, \min )}=1.14\right)$

$[\mathrm{kPa}]$

$\begin{array}{llll}-1.5 & -1 & -0.5 & 0\end{array}$

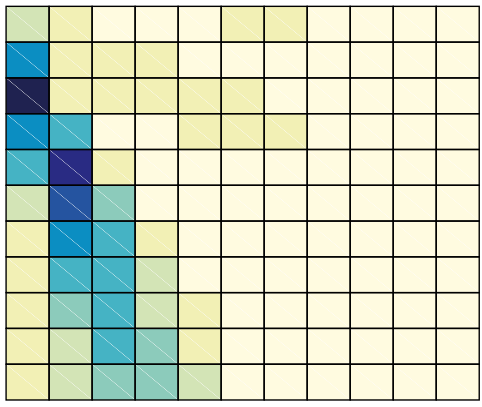

Structural responses

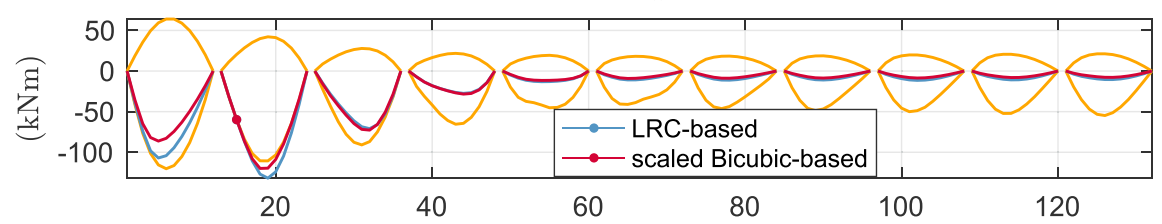

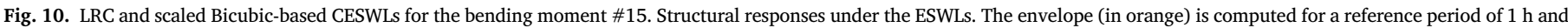
the $86 \%$-quantiles extremes. (For interpretation of the references to colour in this figure legend, the reader is referred to the web version of this article.)
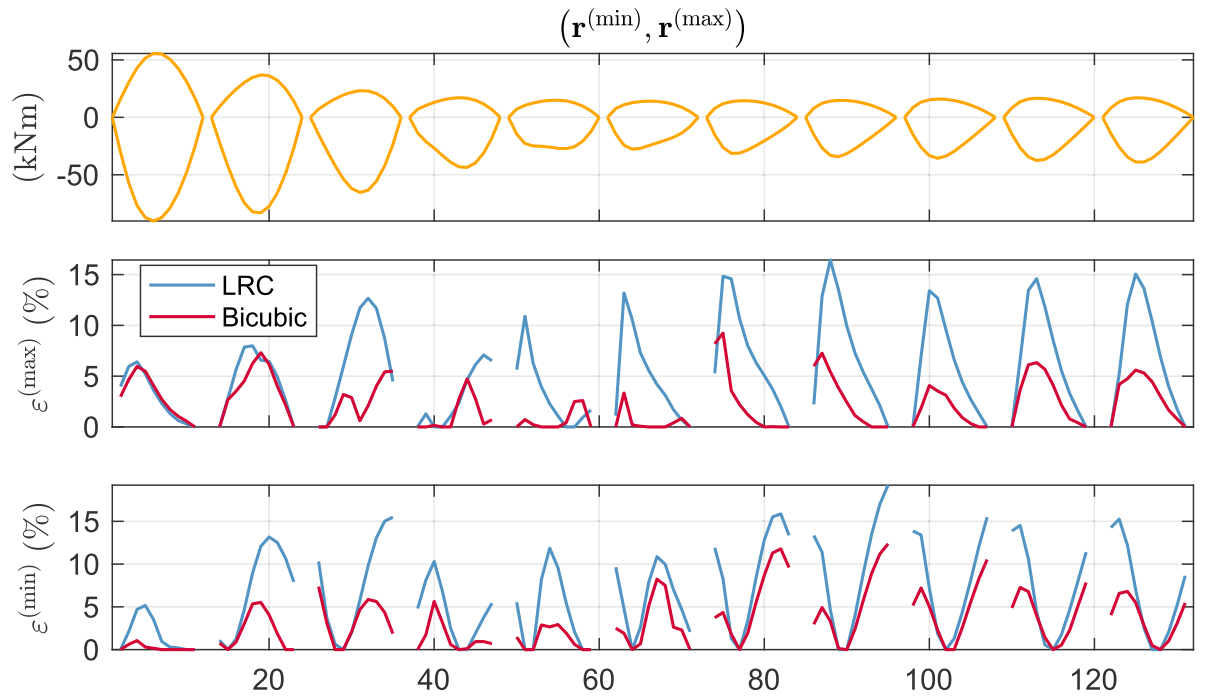

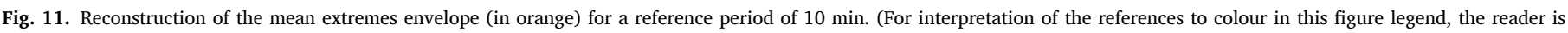
referred to the web version of this article.) 


\subsection{Structural responses under equivalent static wind loads}

This section aims at comparing the LRC and bicubic-based CESWLs. In order to compute bicubic-based CESWLs, the monotone limitation has to be fulfilled. Fig. 8 depicts the skewness and excess coefficients for the aerodynamic pressures and the bending moments. A significant number of processes are close to and outside the monotone limitation. When necessary, the vertical mapping consisting in finding on the monotone limitation the skewness coefficient for the exact excess coefficient is applied, as recommended in (Peng et al., 2014).

The reference period of $1 \mathrm{~h}$ and the 86\%-quantiles extremes envelope are considered to illustrate the ESWLs. Fig. 9 illustrates the ESWLs for the negative extreme of the bending moment $\# 20$, which is located approximately at two thirds of the span in the second beam. Both ESWLs are similar and thus so are the structural responses. For this particular envelope value, there is no overestimation of the envelope. The scaling coefficient of the original bicubic-based CESWL is $\alpha^{(\mathrm{s}, \min )}=1.09$, i.e., the original CESWL is amplified to perfectly recover the considered envelope.

Fig. 10 shows the ESWLs for the negative extreme of the bending moment \#15. The ESWLs are not similar, the largest loading for the second beam is not at the same location. For this particular envelope value, there are overestimations of the envelope for the bending moments \#16-17-19-20-21-22-23. The largest overestimation is $20 \%$ with LRC ESWL and $5 \%$ for scaled bicubic-based CESWL. The scaling coefficient of the original bicubic-based CESWL is $\alpha^{(\mathrm{s}, \min )}=1.14$, i.e., the original CESWL is amplified to recover perfectly the considered envelope.
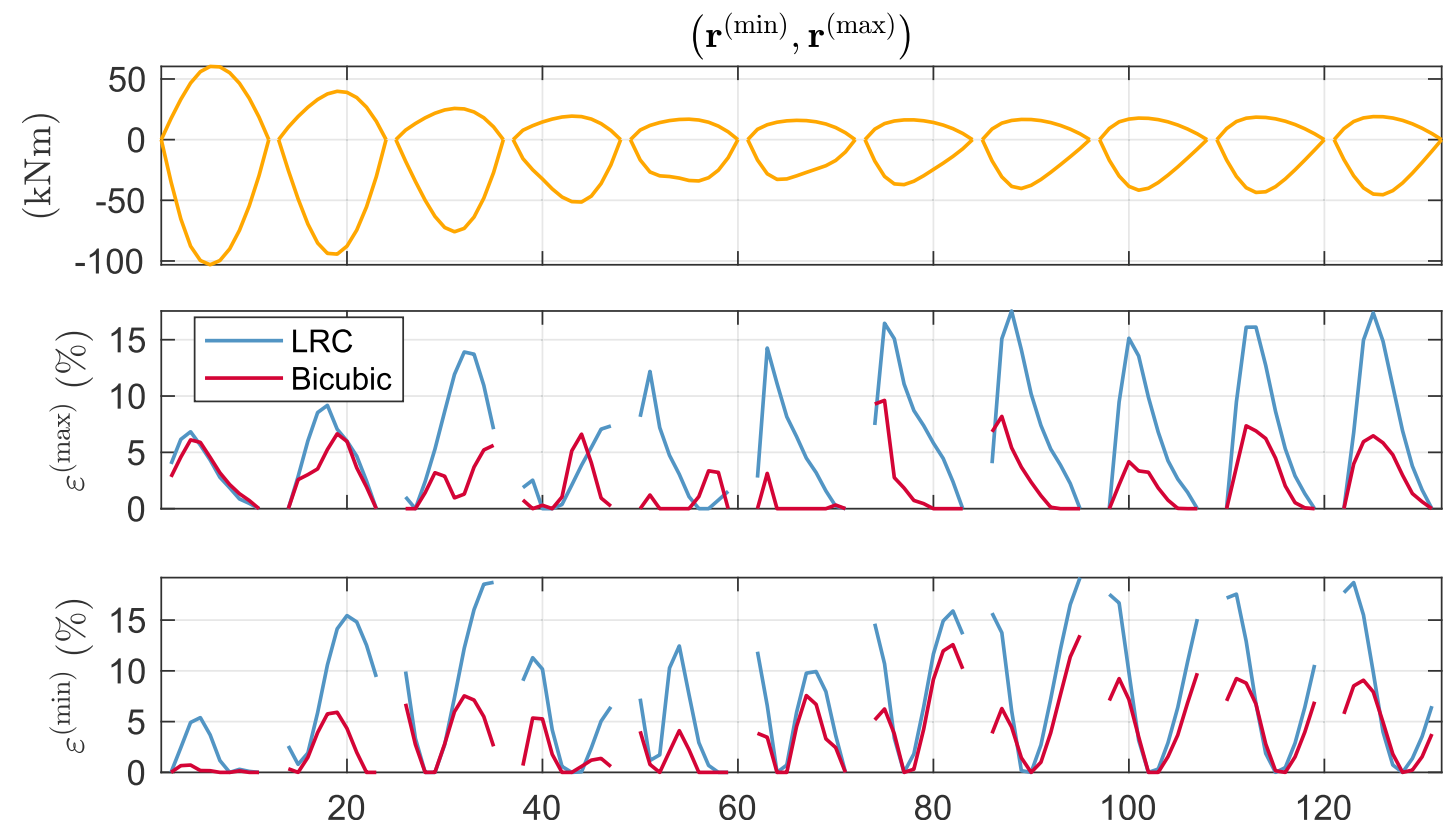

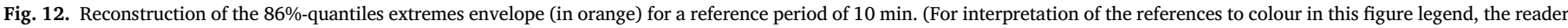
is referred to the web version of this article.)
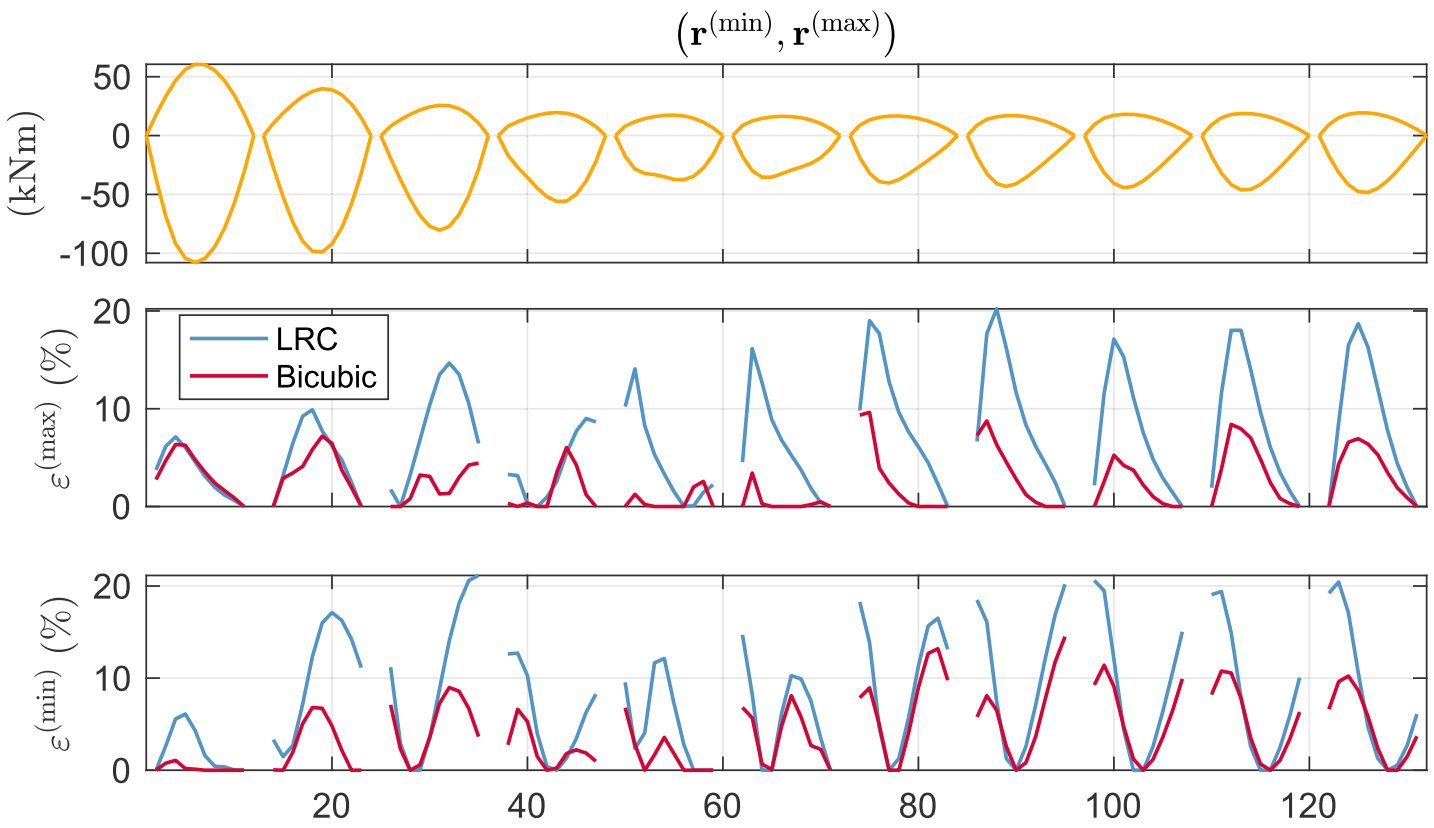

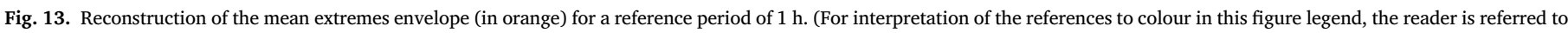
the web version of this article.) 


\subsection{Assessment of extreme value overestimations}

ESWLs are computed for various reference periods and quantiles values, and for all bending moments except at supports. Overestimations for the positive and negative extremes are then estimated as explained in Section 3.

\subsubsection{Reference period of $10 \mathrm{~min}$}

For a reference period of $10 \mathrm{~min}$, Figs. 11 and 12 illustrate the reconstruction of the mean extremes envelope and the 86\%-quantiles extremes envelope, respectively. Relative errors up to $18 \%$ are observed and these overestimations are larger with the LRC method than with the bicubic model. Considering a higher statistics of process extremes with the $86 \%$-quantiles seems to slightly increase the overestimations. The chosen statistics of process extremes (mean or 86\%-quantile) does not influence the pattern of overestimations. Using the bicubic model keeps the overestimations below around $10 \%$.

\subsubsection{Reference period of $1 \mathrm{~h}$}

For a reference period of $1 \mathrm{~h}$, Figs. 13 and 14 illustrate the reconstruction of the mean extremes envelope and the $86 \%$-quantiles extremes envelope, respectively. Similar observations as in Section 4.4.1 can be outlined, however, the level of overestimations is larger, up to $25 \%$ with the LRC method and up to $15 \%$ for the bicubic model. The reference period does not change the pattern of overestimations. For most responses, using the bicubic model instead of the LRC method permits to decrease significantly the overestimations.

\section{Summary and conclusions}

Fig. 15 is an integrated graphical representation of the overestimations provided in Figs. 11-14. It summarizes the overestimations computed for the two considered methods ( $\mathrm{x}$ - and y-axes of the graph), for the two reference periods, and the two types of extreme value (mean extreme or $86 \%$-quantile). This graph shows that the bicubic-based CESWLs generally perform better, but not always. When the overestimation is smaller than $10 \%$, the bicubic-based CESWL may provide slightly larger overestimations than the LRC ESWL. It consistently performs better, however, for larger overestimations.

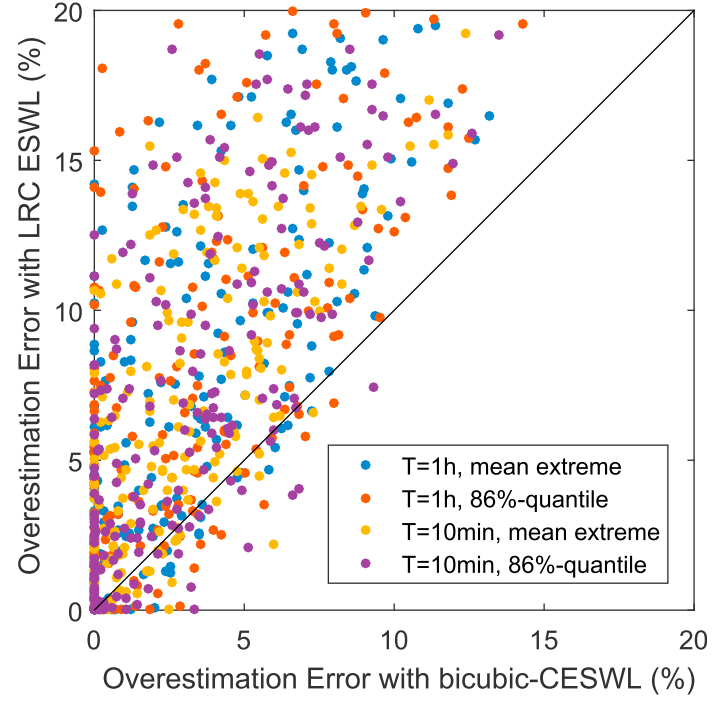

Fig. 15. Summary of the overall performance of the bicubic-based CESWL. One-to-one correspondences of the overestimations, in \%, provided by the LRC and bicubic-based CESWL, corresponding to the four cases detailed in Figs. 11-14.

In conclusion, the assessment of extreme value overestimations with equivalent static wind loads is presented on a rigid flat-roof low-rise building. A wind tunnel experiment, composed of $371.8 \mathrm{~h}$ (full-scale) of measurement, is used to compare the overestimations produced by the scaled CESWL based on a bicubic model and by the LRC method.

It is observed that large overestimations of the envelope values of structural responses occur with the LRC-method, up to $25 \%$. Smaller overestimations, around 15\%, are achieved with the bicubic model. This constitutes a certain improve towards a reliable and economical windresistant design. This study reveals that larger overestimations of the envelope are produced when design values are defined with a smaller probability of occurrence (86\%-quantile vs mean extreme) and with a larger reference period ( $1 \mathrm{~h}$ vs $10 \mathrm{~min}$ ). The reference period as well as the statistics of the process extremes do not significantly change the pattern of overestimations.

The bicubic model was designed to keep (13) simple enough, while
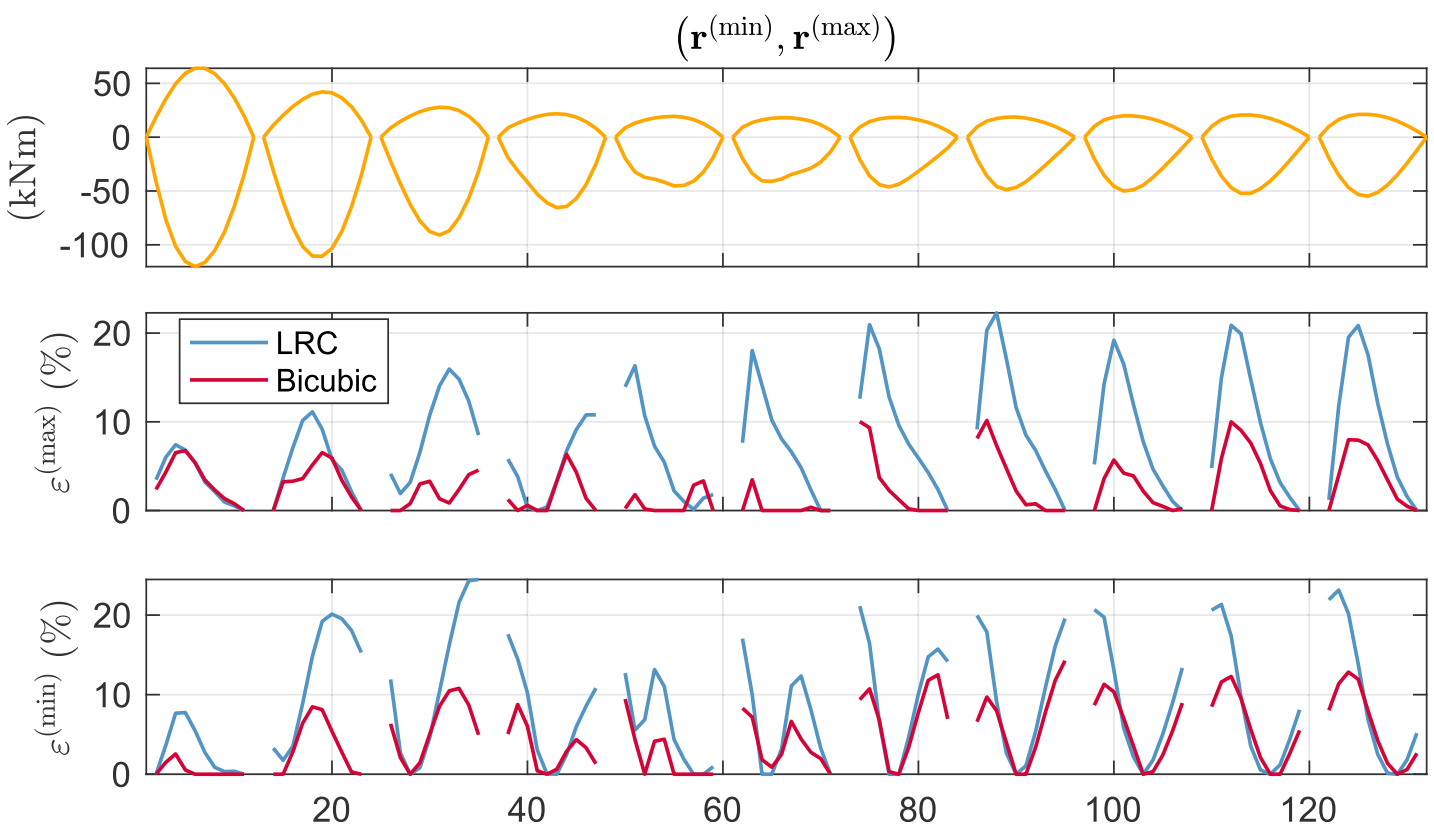

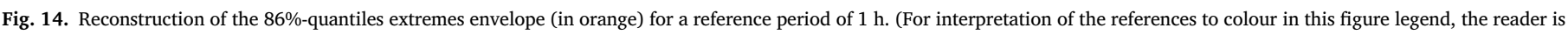
referred to the web version of this article.) 
offering some 7 degrees-of-freedom to better match the non-Gaussian joint probability density function of the wind load and structural response. This study shows that a systematic application of equation (13) instead of (15), although a little bit more involved, results in a more accurate solution of the reconstruction of the envelope through equivalent static wind loads. Yet, some other models, maybe more sophisticated, could be designed in order to keep the expression of the conditional load simple enough but providing more degrees-of-freedom and a better match with the actual joint probability density function of wind load and structural response.

This paper has only discussed the quality of the reconstruction of the envelope, by considering all CESWLs associated with all structural responses of interest. It could become an issue to design large structures, with this very large set of static loads. In the author's former works, various methods have been studied and compared in order to reduce this large set of loads down to a bunch of load cases without degrading the quality of the reconstruction (Blaise et al., 2016).

\section{References}

Bergh, H., Tijdeman, H., 1965. Theoretical and Experimental Results for the Dynamic Response of Pressure Measuring Systems. National Aero and Aeronautical Research Institute NLR-TR F.238.

Blaise, N., Denoël, V., 2013. Principal static wind loads. J. Wind Eng. Indus. Aerodyn. 113, 29-39.

Blaise, N., Canor, T., Denoël, V., 2016. Reconstruction of the envelope of non-gaussian structural responses with principal static wind loads. J. Wind Eng. Indus. Aerodyn. $149,59-76$.

Chen, X.Z., Kareem, A., 2001. Equivalent static wind loads for buffeting response of bridges. J. Struct. Eng. Asce 127, 1467-1475.

Chen, X., Zhou, N., 2007. Equivalent static wind loads on low-rise buildings based on fullscale pressure measurements. Eng. Struct. 29, 2563-2575.

Davenport, A.G., 1967. Gust loading factors. In: Proceedings of the American Society of Civil Engineers J. Struct. Div. 93, 11-34.

Ding, J., Chen, X., 2014. Assessment of methods for extreme value analysis of nongaussian wind effects with short-term time history samples. Eng. Struct. 80, 75-88.

Eurocode, E., 1991. EN 1991-1-3: Actions on Structures-General Actions-Wind Actions. European Committee for Standardization.

Gurley, K.R., Tognarelli, M.A., Kareem, A., 1997. Analysis and simulation tools for wind engineering. Probabilistic Eng. Mech. 12, 9-31.

Holmes, J.D., 1988. Distribution of peak wind loads on a low-rise building. J. Wind Eng. Indus. Aerodyn. 29, 59-67.

Holmes, J.D., 1994. Along-wind response of lattice towers: part i - derivation of expressions for gust response factors. Eng. Struct. 16, 287-292.
Holmes, J.D., Best, R.J., 1981. An approach to the determination of wind load effects on low-rise buildings. J. Wind Eng. Indus. Aerodyn. 7, 273-287.

Huang, G.Q., Chen, X.Z., 2007. Wind load effects and equivalent static wind loads of tall buildings based on synchronous pressure measurements. Eng. Struct. 29, 2641-2653.

Kasperski, M., 1992. Extreme wind load distributions for linear and nonlinear design. Eng. Struct. 14, 27-34.

Kasperski, M., Niemann, H.J., 1992. The 1.r.c. (load-response-correlation) - method a general method of estimating unfavourable wind load distributions for linear and non-linear structural behaviour. J. Wind Eng. Indus. Aerodyn. 43, 1753-1763.

Katsumura, A., Tamura, Y., Nakamura, O., 2007. Universal wind load distribution simultaneously reproducing largest load effects in all subject members on large-span cantilevered roof. J. Wind Eng. Indus. Aerodyn. 95, 1145-1165.

Kawai, H., Nishimura, G., 1996. Characteristics of fluctuating suction and conical vortices on a flat roof in oblique flow. J. Wind Eng. Indus. Aerodyn. 60, 211-225.

Kind, R., 1986. Worst suctions near edges of flat rooftops on low-rise buildings. J. Wind Eng. Indus. Aerodyn. 25, 31-47.

Li, Y.Q., Wang, L., Tamura, Y., Shen, Z.Y., 2009. Universal equivalent static wind load estimation for spatial structures based on wind-induced envelope responses. In: Symposium of the International Association for Shell and Spatial Structures (50th. Valencia).

Lou, W., Zhang, L., Huang, M.F., Li, Q.S., 2015. Multiobjective equivalent static wind loads on complex tall buildings using non-gaussian peak factors. J. Struct. Eng. 141.

Patruno, L., Ricci, M., de Miranda, S., Ubertini, F., 2017. An efficient approach to the determination of equivalent static wind loads. J. Fluids Struct. 68, 1-14.

Peng, X., Yang, L., Gavanski, E., Gurley, K., Prevatt, D., 2014. A comparison of methods to estimate peak wind loads on buildings. J. Wind Eng. Indus. Aerodyn. 126, 11-23.

Repetto, M.P., Solari, G., 2004. Equivalent static wind actions on vertical structures. J. Wind Eng. Indus. Aerodyn. 92, 335-357.

Simiu, E., 1973. Gust factors and alongwind pressure correlations. ASCE J. Struct. Div. 99, 773-783.

Simiu, E., Scanlan, R., 1996. Wind Effects on Structures, third ed. John Wiley and Sons.

Solari, G., 1993a. Gust buffeting. i: peak wind velocity and equivalent pressure. J. Struct. Eng. N. Y. 119, 365-382.

Solari, G., 1993b. Gust buffeting. ii: dynamic alongwing response. J. Struct. Eng. N. Y. 119, 383-398.

Stathopoulos, T., 1984. Wind loads on low-rise buildings: a review of the state of the art. Eng. Struct. 6, 119-135.

Tamura, Y., Fujii, K., Ueda, H., 1992. Design wind loads for beams supporting flat roofs. J. Wind Eng. Indus. Aerodyn. 43, 1841-1852.

Vickery, B., 1970. On the reliability of gust loading factors. In: Proceedings of the Technical Meet Concerning Wind Loads on Buildings and Structures. National Bureau of Standards, Washington, pp. 93-104.

Winterstein, S.R., 1988. Nonlinear vibration models for extremes and fatigue. J. Eng. Mech. 114, 1772-1790.

Winterstein, S.R., Kashef, T., 2000. Moment-based load and response models with wind engineering applications. J. Sol. Energy Eng. 122, 122-128.

Yang, L., Gurley, K.R., Prevatt, D.O., 2013. Probabilistic modeling of wind pressure on low-rise buildings. J. Wind Eng. Indus. Aerodyn. 114, 18-26.

Zhou, X., Gu, M., Li, G., 2011. Application research of constrained least-squares method in computing equivalent static wind loads. In: Proceedings of the 13th International Conference on Wind Engineering. 